\title{
The Care Programme Approach: time for frank talking
}

\author{
Tom Burns and Judy Leibowitz
}

The Care Programme Approach (CPA) was introduced as a cornerstone of the Government's mental health policy in 1992 (Kingdon, 1994). It was meant to clarify the complex issues surrounding the coordination of care for the severely mentally ill and to promote interprofessional communication and effective targeting of resources by community mental health teams (CMHTs). The Ritchie report into the care of Christopher Clunis (Ritchie, 1994) underlined the need for clarity about who has overall responsibility for coordination and review of the progress of care - the key worker. The report makes a compelling case for a clearly documented care plan with identified problems, therapeutic goals and an unambiguous statement of who is responsible for what and when. How, then, could this virtuous proposal generate conflict and bad feeling? And why is there relatively little debate about it in the professional press?

We consider that the ambiguous status of the CPA (is it a therapeutic strategy or an administrative process?) hinders debate. Marshall (1995) links the CPA to the development of care management and case management, and insists that as government policy (rather than professional practice) it cannot be properly subject to evaluation. Case management is brought into the confusion along with care management and the Care Programme Approach. A recent editorial in the Lancet, "Care management: a disastrous mistake" (1996) and one in the British Medical Journal, "Case management: ineffective and unproven yet government policy" (Marshall, 1995) tar them all with the same brush and dismiss them as costly encumbrances which offer nothing for patients and simply soak up professionals' time.

All three terms do have things in common besides sounding confusingly similar. There is a historical development of community mental health practice which links them and illuminates both their crucial similarities and differences. Understanding this history, and acknowledging that language changes to reflect practice rather than determining it, could resolve the present adversarial position, promoting change and development.

The first case managers in the US, responding to the discharge of long-term patients from mental hospitals, were non-clinicians who ensured that patients had access to appropriate medical and social support (Intagliata, 1982). Their role was primarily advocacy and obtaining services hence the term 'brokerage case management'. Rigorous evaluation confirmed clinical impressions that this approach was expensive and unhelpful (Curtis et al, 1992; Franklin et al, 1994). Unfortunately, it is this model of brokerage case management which appears to have been adopted by British social services as "care management' in the wake of the Griffiths report (Griffiths, 1988). British studies of this approach (Tyrer et al, 1995; Marshall et al, 1995) are no more encouraging in terms of maintaining patients in the community, although Tyrer and colleagues demonstrated improved continuity of contact.

Clinical case management evolved from the discredited brokerage model. In this approach the case manager is a health or social services professional responsible for much of the direct care for the patient. Elements of advocacy and brokerage remain, but the emphasis is on direct care. The approach is characterised by breadth of remit and an acceptance of tasks not normally considered professional - direct help with shopping or cleaning, accompanying the patient on recreational outings, and so on. This approach gained international acclaim with the publication of a study of the PACT model in Madison, Wisconsin (Stein \& Test, 1980). Since then there has been a growing convergence of case management models to emphasise small case loads targeting specific clinical groups, and stressing assertive community-based work. This approach has been extensively researched in the US (Solomon, 1992; Burns \& Santos, 1995), and repeatedly demonstrated to benefit patients, often with cost savings. Replications have been studied outside the US with substantially similar results (Hoult et al, 1983; Muijen et al, 1992), although the advantages over standard care are variable and have diminished over time.

The CPA derives much of its thinking from clinical case management. The role of the key worker clearly stems from that of the case manager, although it is rarely as intensive. He or she is responsible for engagement and regular 
contact with the patient, setting treatment goals and regularly reviewing progress. He or she is part of a team and expected to coordinate care and involve other appropriate team members. Such practices were already identifiable in British services with an interest in community mental health (Burns, 1990), although not labelled as such.

While the two forms of case management should be easily and profitably distinguished from each other, there remain forces blurring the distinction. This is most evident in attempts to integrate the paperwork for care management and CPA. The price paid for this triumph of bureaucratic tidiness is continuing fuzzy thinking and a failure to acknowledge real differences in philosophy - a recipe for a sterile, wearing partnership.

\section{A proposal}

Firstly, a positive, sustained effort should be made to distinguish these three concepts. Confusion between care management and clinical case management needs to be consistently challenged in journals and in local policy documents. Authors who use the terms interchangeably (Muijen et al, 1994) or broadly (Tyrer et al, 1995) should be encouraged to give clearer descriptions of exactly what they are reporting.

Secondly, mental health clinicians should acknowledge that the CPA, as presently promulgated, is a mixture of good clinical sense (which can ensure that sensible, minimal standards are met) and administrative absurdity. It doesn't help, however, to wage guerrilla warfare or to sulk and refuse to cooperate (more common than generally acknowledged). One way forward would be for common (as opposed to exemplary) clinical practice of the CPA to be more fully described and debated.

In this spirit we present a brief overview of how we apply the CPA in the North Battersea CMHT. This is a small (half-time) team of seven wholetime equivalent professionals serving a deprived population of 20000 in the inner city Borough of Wandsworth. It has the benefit of excellent relationships with the local authority Social Services (with 1.5 social workers fully integrated into the team), and is aligned with three large group practices from whom it gets most of its referrals and with whom there is well-established liaison. There is a long tradition of multidisciplinary working prioritising the ongoing care of the severely mentally ill (McLean \& Leibowitz, 1990). It is part of a university service and emphasises home-based assessment and care. On the down side it has many part-time members, only one full-time community psychiatric nurse (CPN), and the in-patient services are four miles away in a forbidding Victorian mental hospital building.

\section{The Care Programme Approach}

We use the term CPA only for those patients with complex needs and for whom there is regular multidisciplinary review. We see nothing to be achieved in using the term 'minimal CPA' for those patients with simple needs who are only in brief contact with one member of the team. Our working definition of 'brief is less than three months or eight contacts. If, at the assessment review (Burns, 1990), it is anticipated that treatment will last for more than three months or eight sessions the patient is entered into the CPA book. If not the professionals confine themselves to their entries in the clinical notes (these are multidisciplinary) and appropriate letters. All are briefly reviewed with the team at discharge. The patient can be entered into the CPA at any time if the assessment of their needs changes.

Patients who are considered to need the CPA are reviewed by the whole team as part of our regular weekly team meeting and not in addition to it. At present there are 95 patients on CPA. Being a small team with so many part-timers, it is important for knowledge about long-term clients to be well distributed. We have also found that some of the most imaginative and facilitative comments about management come from those whose involvement would not have been predicted from the existing elements of the care plan. For instance, the occupational therapist may comment on a recently opened support group which is just right for a client for whom structure and support were not previously identified needs. Similarly, the psychologist could offer to supervise grief work for a schizophrenic patient whose present difficulties had not been construed in this way until the review.

We have decided on a routine review interval of six months (three months for those on the supervision register). Patients whose condition is unstable or worrying can be reviewed earlier. Where there has been a major change in management we routinely suggest review at three months. Intercurrent crises are reviewed as part of the routine community team meeting. The frequency of the reviews reflects competing priorities and we are in no way certain that our decision is optimal. The configuration of our team favours six-monthly, well-distributed, upto-date knowledge. We have good local GPs and until recently, excessive case loads. Reviewing six-monthly helped us to identify, across the team, patients sufficiently stable to be discharged back to their GPs. This works both by making obvious those with stable care-plans and settled lives, and also by functioning as a rough 
bench-mark - if the management doesn't need reviewing more than once a year, does it really need input from a specialist team?

Such frequent reviews introduce time constraints. A six-monthly cycle requires 190 reviews a year and we had already decided not to allocate more than half our weekly community meeting to them. This means five reviews a week of only 15 minutes, whereas on a 12-months' cycle they could be allocated 30 minutes. In terms of presenting a summary and discussing the relevant issues, 15 minutes seems to work well for us. It's tight, but not rushed, and the level of detail presented seems to match what most team members can hold in their heads. It also fosters brevity - an essential training experience for key workers. Obviously, flexibility is required. It is not possible, however, to have the client routinely present and real discipline is required when outside professionals attend. It also makes it difficult to present any structured assessments (e.g. needs assessment or symptom schedules), which have major benefits for reviewing very long-term patients.

Attendance of the client at CPA reviews is generally assumed to be good practice. Our approach does not include it. We question whether the guidance makes good clinical sense. We know that patients find large meetings such as ward rounds stressful (Foster et al, 1991) and they are even less likely to know all the members of the CMHT. We have also had direct feedback about how stressful patients have found these meetings. This does not mean that they are not involved in their care-programming or only see their key worker. Key workers discuss the care plan with the patient in the weeks leading up to the review. We have recently introduced a routine of showing patients their care plans, ensuring that they understand them, and inviting them to make suggestions. If they want a copy they are given one. Similarly we ensure that any patient on long-term antipsychotics is reviewed at least once a year by a team doctor, and this is invariably in association with the key worker when overall progress is discussed. This is not part of the CPA review, but usually takes place in the patient's home or in out-patients.

We have a flexible approach to who should have a copy of the care-plan. This is a single A4 sheet which has supervision register details and contingency plans on the back if appropriate (copies available on request from the authors). One of our GP practices wants copies sent routinely, while one has specifically asked not to have them sent. The third practice has expressed no preference and at present we are not sending them. On balance we encourage patients to know as much as possible about their problems and about our understanding of them (Kosky \& Burns, 1995), so would favour them having copies of their care plans. Judgement needs to be exercised about the risk of them being left on the bus or lying around. We see real benefits to both patient and key worker (in accountability for content) of such access.

When patients are on the supervision register this is recorded on their care plan. The risk factors, reason for inclusion and brief contingency plan are summarised on the back and a copy kept centrally for out-of-hours access. Similarly, where costed care management is involved this is indicated on the care plan along with details of who is responsible for it and has authorised it. More detailed care management documents are kept separately.

\section{Conclusions}

The Care Programme Approach is a hybrid, and like many hybrids may prove hardy. Clinically it derives from case management with its tradition of targeting and comprehensive provision for the most vulnerable. Its present position in British mental health care, however, stems as much from the political necessity of being seen to be doing something to prevent disasters. Lacking a secure, clinically informed mechanism for targeting its use, the Department of Health has gone for global coverage. It is this insistence that all patients under the care of the secondary services must be subject to the Care Programme Approach which obscures its real benefits for those with complex needs. Face-saving concepts such as 'tiered CPA' simply confuse and discredit the approach by generating Orwellian phrases such as 'minimal CPA' to mean no CPA.

Keeping the decision about which patients are on CPA clinical rather than administrative highlights its value and allows the team to own it. The ease of auditing this approach to CPA (how many patients are on it, what are their diagnoses, the range of their needs, the frequency of review, etc.) provides a mechanism for monitoring practice which should meet the legitimate requirements of managers, purchasers and the Department of Health. Pathfinder Mental Health Trust has just introduced Trust-wide CPA documentation which will facilitate just such monitoring.

Many aspects of our North Battersea practice (frequency of review, criteria for inclusion, etc.) will change and evolve with experience. We have found the CPA, applied as part of the clinical decision-making process (rather than the determinant of that decision-making), to be a valuable tool and would encourage others to describe how they have absorbed it into their practice. 


\section{References}

BuRNS, B. J. \& SANTOS, A. B. (1995) Assertive community treatment: an update of randomized trials. Psychiatric Services, 46, 669-675.

BuRns, T. (1990) Community ward rounds. Health Trends, 22, 62-63.

Curtis, J. L., Millman, E. J., Struening, E., et al (1992) Effect of case management on rehospitalisation and utilisation of ambulatory care services. Hospital and Community Psychiatry, 43, 895-899.

Foster, H. D., FALKOWSK, W. \& Rollings, J. (1991) A survey of patients' attitudes towards inpatient psychiatric ward rounds. International Journal of Social Psychiatry, 37. 135-140.

Frankuin, J. L., Solovitz, B., Mason, M., et al (1994) An evaluation of case management. American Journal of Public Health, 77, 674-678.

GRIFFITHS, R. (1988) Community Care: Agenda for Action. London: HMSO.

Hoult, J., Reynolds, I., Charbonneau-Powis, M., et al (1983) Psychiatric hospital versus community treatment: the results of a randomised trial. Australian and New Zealand Journal of Psychiatry, 17, 160-167.

INTAGLATA, J. (1982) Improving the quality of community care for the chronically mentally disabled: the role of case management. Schizophrenia Bulletin, 8, 655-674.

KIngDon, D. (1994) Care Programme Approach: Recent Government policy and legislation. Bulletin of the Royal College of Psychiatrists, 18, 68-70.

Kosky, N. \& BURNS, T. (1995) Patient access to psychiatric records: experience in an in-patient unit. Psychiatric Bulletin, 19, 87-90.

LANCET (1996) Care-management: a disastrous mistake. Editorial. Lancet, 345, 399-401.

MARSHALL, M. (1995) Case management: a dubious practice. Under evaluated and ineffective, but now governmen policy. British Medical Journal, 312, 523-524.
- LOCKwood, A. \& GATH, D. (1995) Social services casemanagement for long-term mental disorders: a randomised controlled trial. Lancet, 348, 409-412.

MCLEAN, E. \& LEIBOWITZ, J. (1990) A community mental health team to serve revolving door patients: the Doddington Edward Wilson (DEW) Mental Health Team 1984-1988. International Joumal of Social Psychiatry, 36, 172-182.

MuLEN, M., MARKS, I. M., CoNnOLly, J., et al (1992) The Daily Living Programme: preliminary comparison of community versus hospital-based treatment for the seriously mentally ill facing emergency admission. British Journal of Psychiatry, 160, 379-384.

-. CoOney, M., STRATHDeE, G., et al (1994) Community psychiatric nurse teams: intensive support versus generic care. British Journal of Psychiatry, 165. 211217.

RrTCHIE, H. G. (1994) The Christopher Clunis Inquiry. London: HMSO.

Solomon. P. (1992) The efficacy of case management services for severely mentally disabled clients. Community Mental Health Journal, 28, 163-180.

STEIN, L. I. \& TEST, M. A. (1980) Alternative to mental hospital treatment. (1) Conceptual model, treatment program, and clinical evaluation. Archives of General Psychiatry, 37, 392-397.

TYRER, P., MORGAN, J., VAN HORN, E., et al (1995) A randomised controlled study of close monitoring of vulnerable patients. Lancet, 345, 756-759.

-Tom Burns, Professor of Community Psychiatry: and Judy Leibowitz, Consultant Clinical Psychologist, Pathfinder Mental Health NHS Trust, Springfield Hospital, 61 Glenburnie Road. London SW17 7DJ 